\title{
Flat-arched feet display altered foot kinematics compared to normal-arched feet during walking
}

\author{
Pazit Levinger ${ }^{1}$, George S Murley ${ }^{1,2^{*}}$, Christian J Barton ${ }^{1}$, Matthew P Cotchett ${ }^{1,2}$, Simone R McSweeney ${ }^{2}$, \\ Hylton B Menz ${ }^{1}$
}

From Australasian Podiatry Council Conference 2011

Melbourne, Australia. 26-29 April 2011

\section{Background}

Foot posture is thought to influence predisposition to overuse injuries of the lower limb. Although the mechanisms underlying this proposed relationship are unclear, it is thought that altered foot kinematics may play a role. Therefore, this study was designed to investigate differences in foot motion between people with normal and flat-arched feet using the Oxford Foot Model (OFM).

\section{Methods}

Nineteen participants with normal- and flat-arched feet were recruited for this study (10 with normal and 9 with flat-arched feet). A foot screening protocol comprising measurements from weightbearing antero-posterior and lateral foot radiographs were used to classify foot posture. Tri-planar motion of the tibia, rearfoot and forefoot during barefoot walking were recorded from 10 cameras and evaluated using a three-dimensional motion analysis system incorporating a multi-segment foot model (OFM).

\section{Results}

During midstance phase, participants with flat-arched feet demonstrated greater forefoot abduction $\left(-12.9^{\circ} \pm\right.$ $6.9^{\circ}$ vs $\left.-1.8^{\circ} \pm 6.3^{\circ} ; \mathrm{p}=0.002\right)$, rearfoot internal rotation $\left(10.6^{\circ} \pm 7.5^{\circ}\right.$ vs $\left.-0.2^{\circ} \pm 9.9^{\circ} ; \mathrm{p}=0.018\right)$ and a trend towards increased rearfoot eversion $\left(-5.8^{\circ} \pm 4.4^{\circ}\right.$ vs $-2.5^{\circ}$ $\pm 2.6^{\circ} ; \mathrm{p}=0.06$ ), compared to those with normal-arched feet. During late stance, participants with flat-arched feet demonstrated greater peak forefoot plantarflexion $\left(-13.7^{\circ} \pm 5.6^{\circ}\right.$ vs $\left.-6.5^{\circ} \pm 3.7^{\circ} ; \mathrm{p}=0.004\right)$ and decreased

\footnotetext{
* Correspondence: g.murley@latrobe.edu.au

${ }^{1}$ Musculoskeletal Research Centre, Faculty of Health Sciences, La Trobe University, Bundoora, VIC, 3086, Australia

Full list of author information is available at the end of the article
}

peak forefoot adduction $\left(-7.0^{\circ} \pm 9.2^{\circ}\right.$ vs $5.6^{\circ} \pm 7.3^{\circ} ; \mathrm{p}=$ 0.004) compared to those with normal-arched feet.

\section{Conclusions}

The findings of this study indicate that there are significant differences in sagittal and transverse plane movement of the forefoot and the transverse plane movement of the rearfoot between participants with normal- and flat-arched feet. These findings support the notion that those with flat-arched feet demonstrate altered motion associated with greater pronation during gait; factors that may increase the risk of overuse injury.

\section{Author details}

${ }^{1}$ Musculoskeletal Research Centre, Faculty of Health Sciences, La Trobe University, Bundoora, VIC, 3086, Australia. ${ }^{2}$ Department of Podiatry, Faculty of Health Sciences, La Trobe University, Bundoora, VIC, 3086, Australia.

\section{Published: 20 May 2011}

doi:10.1186/1757-1146-4-S1-P43

Cite this article as: Levinger et al:. Flat-arched feet display altered foot kinematics compared to normal-arched feet during walking. Journal of Foot and Ankle Research 2011 4(Suppl 1):P43.

Submit your next manuscript to BioMed Central and take full advantage of:

- Convenient online submission

- Thorough peer review

- No space constraints or color figure charges

- Immediate publication on acceptance

- Inclusion in PubMed, CAS, Scopus and Google Scholar

- Research which is freely available for redistribution 